\title{
Protein profile and protein interaction network of Moniliophthora perniciosa basidiospores
}

Joise Hander Mares ${ }^{1}$, Karina Peres Gramacho ${ }^{1,3}$, Everton Cruz dos Santos ${ }^{1}$, André da Silva Santiago², Edson Mário de Andrade Silva ${ }^{1}$, Fátima Cerqueira Alvim ${ }^{1}$ and Carlos Priminho Pirovani ${ }^{* *}$

\begin{abstract}
Background: Witches' broom, a disease caused by the basidiomycete Moniliophthora perniciosa, is considered to be the most important disease of the cocoa crop in Bahia, an area in the Brazilian Amazon, and also in the other countries where it is found. M. perniciosa germ tubes may penetrate into the host through intact or natural openings in the cuticle surface, in epidermis cell junctions, at the base of trichomes, or through the stomata. Despite its relevance to the fungal life cycle, basidiospore biology has not been extensively investigated. In this study, our goal was to optimize techniques for producing basidiospores for protein extraction, and to produce the first proteomics analysis map of ungerminated basidiospores. We then presented a protein interaction network by using Ustilago maydis as a model.

Results: The average pileus area ranged from 17.35 to $211.24 \mathrm{~mm}^{2}$. The minimum and maximum productivity were 23,200 and 6,666,667 basidiospores per basidiome, respectively. The protein yield in micrograms per million basidiospores were approximately $0.161 ; 2.307$, and 3.582 for germination times of 0,2 , and $4 \mathrm{~h}$ after germination, respectively. A total of 178 proteins were identified through mass spectrometry. These proteins were classified according to their molecular function and their involvement in biological processes such as cellular energy production, oxidative metabolism, stress, protein synthesis, and protein folding. Furthermore, to better understand the expression pattern, signaling, and interaction events of spore proteins, we presented an interaction network using orthologous proteins from Ustilago maydis as a model. Most of the orthologous proteins that were identified in this study were not clustered in the network, but several of them play a very important role in hypha development and branching.

Conclusions: The quantities of basidiospores $7 \times 10^{9} ; 5.2 \times 10^{8}$, and $6.7 \times 10^{8}$ were sufficient to obtain enough protein mass for the three 2D-PAGE replicates, for the 0,2 , and $4 \mathrm{~h}$-treatments, respectively. The protein extraction method that is based on sedimentation, followed by sonication with SDS-dense buffer, and phenolic extraction, which was utilized in this study, was effective, presenting a satisfactory resolution and reproducibility for M. perniciosa basidiospores. This report constitutes the first comprehensive study of protein expression during the ungerminated stage of the M. perniciosa basidiospore. Identification of the spots observed in the reference gel enabled us to know the main molecular interactions involved in the initial metabolic processes of fungal development.
\end{abstract}

Keywords: Basidiospores, Interaction network, Mass spectrometry, Proteomics, Witches' broom

\footnotetext{
* Correspondence: pirovanicp@gmail.com

'Departamento de Ciências Biológicas, Universidade Estadual de Santa Cruz,

Ilhéus, Bahia, Brazil

Full list of author information is available at the end of the article
} 


\section{Background}

Cocoa beans (Theobroma cacao L.) are the raw material for chocolate manufacturing. In South and Central America, production of these beans is affected by several diseases, mainly caused by fungi [1], such as witches' broom disease caused by the basidiomycota Moniliophthora perniciosa [2]. Witches' broom is considered to be the most important disease in tropical America including Bahia, the most important cocoa-producing region in Brazil [3]. The life cycle starts with the release of basidiospores, which are the only infective propagules of the fungus. Basidiospores emerge from basidiomes produced on dry brooms, which are necrotized branches [4]. Basidiospores (n), meiospores of M. perniciosa, are easily carried over short distances by wind and can lead to an epidemic. Early processes of infection include basidiospore attachment, germination, and the formation of a germ tube. The germ tubes differentiate into club-shaped hyphae, which can penetrate into natural openings or wounds. Natural openings include the cuticle surface, the epidermis cell junctions, the base of trichomes, and the stomata [5]. Within $24 \mathrm{~h}$ after spore germination, biotrophic hyphae can be seen in the apoplasts of infected tissues, inducing macroscopic modifications such as the formation of green brooms.

Since basidiospores are the critical inoculum for infection that cocoa encounters in the field, studies that directly examine these spores are critical. In vitro basidiospore production requires basidiospore inoculum free of other contaminating organisms. Protocols for in vitro and in vivo production of $M$. perniciosa basidiospores have been established $[6,7]$. The current techniques to cast basidiospores [8] permit storage of both precise and clean basidiospores as required for efficient studies, i.e. inhibition tests of basidiospore germination, identifying volatile compounds produced by endophyte fungi of cacao [9], screening of cacao genotypes for witches' broom disease [10], and studying fungal biology [11], among others.

The genome and transcriptome resources for $M$. perniciosa have been generated [12, 13]. These data have been used in several studies to reveal many aspects of the Theobroma cacao vs. M. perniciosa interaction. Furthermore, a representative cDNA library of the host-pathogen interaction is also available for the identification of pathogen and host genes involved in pathogenicity and resistance mechanisms [14]. Several studies support efforts to characterize proteins related to metabolic routes during fungal infection [15-21]. For example, the effects of TcPR10, a protein with ribonuclease activity and potential to induce proteome variations in the mycelium, were examined in $M$. perniciosa [22]. Recently, studies identified genes differentially expressed in $M$. perniciosa basidiospores after exposure to Theobroma cacao from high-resolution transcriptomic data [23].
Proteomic studies are needed to broaden the knowledge of $M$. perniciosa metabolism during the initial life cycle phase to enhance the control strategies for this plant pathogen. For instance, proteomic analysis may help us to understand the expression, function, and regulation of specific groups of proteins encoded by the fungal genome [24]. Using this approach, several proteins involved in spore metabolism of plant pathogenic fungi Blumeria graminis f.sp. hordei [25], Aspergillus nidulans [26], and Colletotrichum acutatum have been identified [27]. However, there are still very few molecular studies using $M$. perniciosa [23], probably due to the difficulty to cast and store the high volume of basidiospores needed for protein extraction and analysis.

Data generated by molecular analyses such as large-scale genomics, transcriptomics, and proteomics may be used to build biological system models through computerized analyses offered by systems biology [28]. Systems biology may translate the complex molecular interactions between genotype and phenotype that exist in biological systems. The idea behind systems biology is that cell networks and biological systems are the bridges between genotypes and phenotypes [29]. Inside those networks, the centrality analysis ranks elements in order to identify the most important components [30]. Central vertices in a network are those nodes, which have a functional or structural importance, and they may influence many other vertices through short and direct pathways [31]. Therefore, centrality measures, in general, capture the structural importance of a vertex regarding the rest of the network. According to the importance levels in an interaction, proteins may be defined as nonhub-non-bottleneck, hub-nonbottleneck, nonhub-bottleneck, and hub-bottleneck [32]. According to $\mathrm{Yu}$ et al., in both interaction and regulation networks, bottleneck and hub-bottleneck proteins tend to be essential proteins with a high degree of significance [32].

Interaction analyses of microbial proteins have been performed in fungi, mainly yeast. Yeast interaction networks are now evident and they may be explored, serving as an exemplar model for the most complex eukaryotes $[33,34]$. A polygalacturonase interaction network, MpPG1 and MpPG2, of $M$. perniciosa has been established using orthologous sequences of Neurospora crassa as a model [35]. However, studies related to plant pathogen fungal spores are scarce.

In this study, we monitored spore production and estimated the number of basidiomes and basidiospores, which are produced in the brooms of a susceptible, diseased cacao genotype named Catongo, allowing us to obtain sufficient protein yields for proteomic studies of germination onset. The protein profile of ungerminated spores was established via SDS-PAGE. A total of 178 proteins were identified through mass spectrometry MS/ 
MS. Furthermore, in order to better understand the expression pattern, signaling, and interaction events of spore proteins, we presented an interaction network using Ustilago maydis as a model.

\section{Methods}

For organization purposes, the workflow was prepared using a flowchart of steps (Additional file 1: Figure S1).

\section{Basidiospore production}

Approximately 300 dry brooms (diseased cacao branches) of a susceptible genotype were randomly collected in a field of the Arnaldo Medeiros Experimental Station at the Cocoa Research Center, CEPLAC/CEPEC-Ilhéus, BA, Brazil. Brooms were superficially disinfected with $0.5 \%$ sodium hypochlorite, hung individually within a cabinet, and subjected to a daily regime of $8 \mathrm{~h}$ wet/16 h dry, at a temperature of $25^{\circ} \mathrm{C} \pm 3{ }^{\circ} \mathrm{C}$, with $100 \%$ humidity from August 2010 to July 2011. Basidiospore concentrations were established prior to storage with aid of a Neubauer chamber and by observation under an optical microscope (Bioval L2000A, 40× magnification). Basidiospores were stored in liquid $\mathrm{N}_{2}$, according to methods described by Frias $[4,8]$.

Before basidiospore production, basidiome size was analyzed. Pilei from 2081 basidiomes were measured with the aid of a universal caliper and were divided in 24 groups according to pileus area. The number of pilei per sample ranged from 15 to 204 (Additional file 2: Table S1). The average productivity per pileus area and average productivity per basidiome were established for each sample (Additional file 2: Table S1).

\section{Basidiospore germination and protein extraction}

For protein extraction and germination viability, basidiospores were defrosted on ice, diluted with distilled water to reduce the glycerol concentration to $3 \%$ [8], and were incubated in the dark at $25{ }^{\circ} \mathrm{C}$. The samples were placed between two glass slides, and germination rates and length of germ tubes were monitored and measured under an optical microscope (Bioval L2000A, 40×).

For protein extraction, basidiospores were allowed to germinate; then, they were centrifuged and casted in 3 stages representative of the initial germination phase after germination: (i) ungerminated ( $0 \mathrm{~h}$ treatment), (ii) $2 \mathrm{~h}$ after germination (HAG), and (iii) 4 HAG (Fig. 1). The basidiospore germ tube growth was measured using the formula below (also see Fig. 3).

Germ tube growth $=($ spore diameter + germ tube length $) /$ spore diameter

\section{Protein extraction}

After the appropriate incubation period, basidiospores were sedimented by centrifugation at $5,000 \times g$ for $20 \mathrm{~min}$. The supernatant was discarded and the precipitate was washed in an acetone solution containing $0.07 \% \beta$ mercaptoethanol. Proteins were extracted according to a method based on those described by Meyer and Pirovani $[36,37]$. Samples were sonicated in an ultrasonic processor (GEX $130130 \mathrm{~W}$ ) to rupture basidiospores. Sonication was carried out as five 20-s pulses at 30-s intervals and $70 \%$ amplitude. During the procedure, samples were kept on ice. After sonication, $800 \mu \mathrm{L}$ of phenol, $\mathrm{pH} 8$, was added and samples were vigorously vortexed for $2 \mathrm{~min}$. Afterwards, they were centrifuged for $3 \mathrm{~min}$ at $10,000 \times g$. The upper phase (phenolic phase) was collected and transferred to a fresh tube, then five-fold (v/v) $100 \%$ methanol with ammonium acetate $0.1 \mathrm{~mol} / \mathrm{L}$ was added. Each sample was homogenized and stored at $-20{ }^{\circ} \mathrm{C}$ for $30 \mathrm{~min}$ to precipitate protein. Proteins were recovered by centrifugation at $10,000 \times g$ for $10 \mathrm{~min}$. The precipitate was washed with cold $0.1 \mathrm{~mol} / \mathrm{L}$ ammonium acetate in methanol and $80 \%$ acetone twice, and then it was resuspended in a rehydration buffer $(7 \mathrm{~mol} / \mathrm{L}$ urea, $2 \mathrm{~mol} / \mathrm{L}$ thiourea, $2 \%$ CHAPS (3-3-Cholamidopropyl Dimethylammonio-1-Propanesulfonate), and $0.002 \%$ Bromophenol blue). Proteins were quantified with a

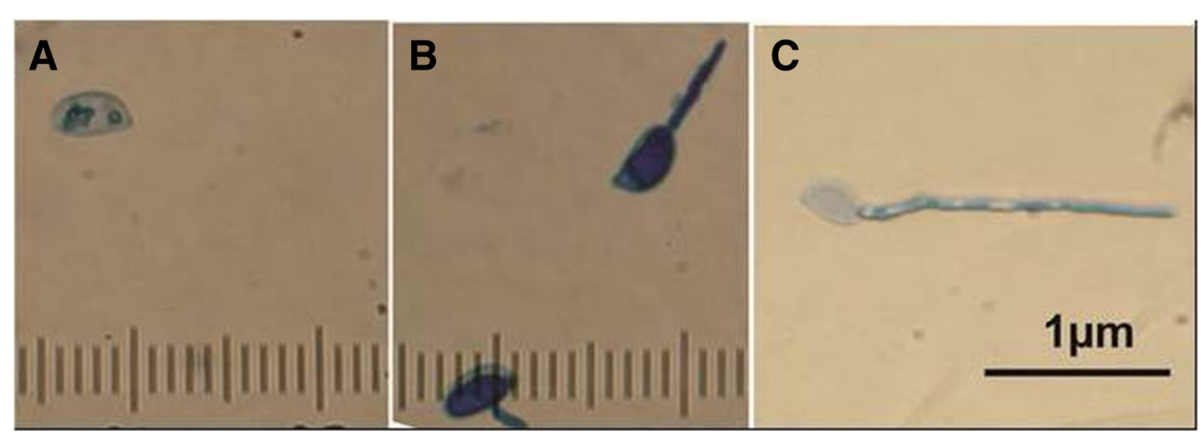

Fig. 1 Morphological differences observed during M. perniciosa basidiospore germination: a ungerminated basidiospore (0 h); b) 2 and c) 4 h after basidiospore germination. Basidiospores were visualized after Cotton Blue staining 
2D-Quant kit (GE HealthCare), following manufacturer's instructions (GE HealthCare) using bovine serum albumin (BSA) as a standard. Samples were stored at $-20{ }^{\circ} \mathrm{C}$ until use.

\section{D and 2D-PAGE}

For the 1D electrophoresis, $30 \mu \mathrm{g}$ of protein from each treatment was separated in $12.5 \%$ polyacrylamide gels using SDS-PAGE in an electrophoresis mini-tray (Omniphor) apparatus measuring $8 \times 10 \mathrm{~cm}$ according to methods described by Laemmli [38].

For the 2D PAGE proteomic analysis, $350 \mu \mathrm{g}$ of protein was used. Protein samples were applied to $13-\mathrm{cm}$ gel strips (containing immobilines) with immobilized $\mathrm{pH}$ ranging from 3 to 10 non-linear (NL) (Amersham Biosciences, Immobiline $^{\text {tw }}$ Dry-Strip). IPG strips were then run in an Ettan IPGphor III Isoelectric Focusing Unit (GE HealthCare) with the following steps: 01:00 h at $500 \mathrm{Vh}, 01: 40 \mathrm{~h}$ at $1000 \mathrm{Vh}, 2: 30 \mathrm{~h}$ at 2,200 $\mathrm{Vh}$, and 04:35 h at $800 \mathrm{Vh}$ ). The current was limited to $50 \mathrm{~mA}$ for each strip, and the temperature was kept at $20{ }^{\circ} \mathrm{C}$ for all focusing steps. After focusing, strips were incubated with $7 \mathrm{~mL}$ of equilibrium buffer containing $1 \%$ DTT for 15 min with slow agitation. Afterwards, they were incubated with equilibrium buffer containing $2.5 \%$ iodoacetamide with slow agitation for $15 \mathrm{~min}$. Finally, the strips were washed with running buffer $(0.025 \mathrm{~mol} / \mathrm{L}$ Tris, $\mathrm{pH}$ 8.3, SDS $0.1 \%$ and $0.19 \mathrm{~mol} /$ L glycine) for $15 \mathrm{~min}$.

The second dimension was performed on a $12.5 \%$ polyacrylamide gel in a HOEFER SE 600 Ruby vertical electrophoresis system (Amersham Bioscience). An initial electrical current of $15 \mathrm{~mA} / \mathrm{gel}$ was applied for $15 \mathrm{~min}$, after which $30 \mu \mathrm{A} / \mathrm{gel}$ was applied for $30 \mathrm{~min}$, and then $50 \mu \mathrm{A} / \mathrm{gel}$ was applied for $3.5 \mathrm{~h}$, totaling a $4.25 \mathrm{~h}$ run. Gels were run in triplicate for each germination time. After Coomassie Blue staining, proteins were unstained with distilled water for 5 days. Triplicates from each treatment were used for informatics evaluation using Image Master V.6 (GE Healthcare) software.

\section{Spot preparation and MS/MS analysis}

All spots found in the ungerminated basidiospores sample gel were excised and processed according to methods described by Silva [22].

Peptides were resolved through reverse-phase chromatography in a nanoAcquity UPLC (WATERS) using two $\mathrm{C}_{18}$ columns, with the first being the "trapping" column (5 $\mu \mathrm{m}, 180 \mu \mathrm{m} \times 20 \mu \mathrm{mm}$ resin), and the second with a $1.7 \mu \mathrm{m}, 100 \mu \mathrm{m} \times 100 \mathrm{~mm}$ resin, under a $0.6 \mu \mathrm{L} / \mathrm{min}$ flow for a 50-min run, and then $4 \mu \mathrm{L}$ of each sample was collected. The peptides were separated according to their acetonitrile gradient; acetonitrile solutions were applied at these concentrations and times: $1 \%$ for $1 \mathrm{~min}$, from 1 to $50 \%$ in $40 \mathrm{~min}$, from 50 to $85 \%$ in $5 \mathrm{~min}, 85 \%$ for another $2 \mathrm{~min}$, from 85 to $1 \%$ in $1 \mathrm{~min}$, and finally $1 \%$ for $2 \mathrm{~min}$, totaling a 50-min run. The separated peptides were ionized in a capillary unit under $3000 \mathrm{~V}$ (Micromass Q-TOFmicro), with fragments in the positive mode having a minimum relative intensity selection of 10 counts. The three most intense ions were analyzed by each 1-s scan, and collision energies ranged from 20 to $49 \mathrm{eV}$ according to the mass/charge $(\mathrm{m} / \mathrm{z})$ ratio of the peptides.

\section{Identification of proteins}

Spectra were processed and analyzed using ProteinLynx Global Server 4.2 software (WATERS) and compared to the NCBI database (http://www.uniprot.org/downloads, October 2012), using the MASCOT MS/MS Ion Search tool (www.matrixscience.com). Both databases were set for tryptic digestion, with one lost cleavage site, and cysteines modified through carbamidomethylation and methionine oxidation, tolerating error for $30 \mathrm{ppm}$ peptides and mass error of MS/MS fragments of $0.1 \mathrm{Da}$. Only significant hits $(p<0.05)$ were accepted according to the MASCOT analysis probability. After identification of the proteins, their ontology and biological function were verified with Uniprot (www.uniprot.org) and were organized into functional categories by BLAST2Go (www.blast2go.com).

\section{System biology analysis}

In order to obtain information on the protein-protein interactions of ungerminated $M$. perniciosa basidiospores, orthologous sequences in $U$. maydis were used (Additional file 3 : Table S4). U. maydis was chosen because it is a basidiomycota fungus that possesses the highest number of sequences orthologous to $M$. perniciosa due to the greater amount of annotated proteins and it is also a well-established model for studying dimorphism, virulence, plant-microbe interactions, and cell biology $[39,40]$. In addition, the genome of this fungus has been annotated substantially [41]. Seventytwo true orthologous sequences (sequences which are found with the best hits) of $U$. maydis were obtained from the reciprocal BLASTp using amino acid sequences of $M$. perniciosa (http://blast.ncbi.nlm.nih.gov/Blast.cgi) with e-values approximately $\leq$ to $10^{-10}$ according to Moreno-Hagelsieb and Latimer [42]. The interaction network was analyzed through Cytoscape software version 2.8.3 [43]. The data were downloaded from the STRING 9.05 database (http:// string-db.org). The following parameters were used for analysis: more than 50 interactions, significance level of 0.6, and addition of nodes until a saturated network was obtained. The MCODE plugin was used to cluster the proteins that had the highest relationships among themselves from the interaction force between them. The BiNGO plugin was used to analyze the biological processes, which were observed in the network in general. 


\section{Results}

\section{Basidiospore productivity}

In order to estimate the quantity of biological material for the production of basidiospores and the subsequent extraction of proteins, basidiocarps were collected and analyzed. We observed that the average pileus area ranged from 17.35 to $211.24 \mathrm{~mm}^{2}$. The minimum and maximum productivities were 23,200 and 6,666,667 basidiospores per basidiome, respectively (Fig. 2). The global spore productivity observed according to the average of amount of pilei per sample, was 744,477 basidiospores per basidiome. When four outlying samples were excluded from the data, an average productivity of 538,446 spores per basidiome was observed. The average productivity of basidiospores per pileus without the previously mentioned four outliers was 405,412 (Additional file 2: Table S1).

\section{Basidiospore germination and germ tube growth}

At $4 \mathrm{~h}$ after germination was initiated, the ratio between germinated and ungerminated basidiospores was approximately 4:1 (Fig. 3a). After that period, spores were stained with Cotton Blue, and no dark-blue color was observed in the basidiospore bodies. However, an intense blue color was observed throughout the germ tubes (Fig. 3b).

\section{Protein yield}

Based on the number of obtained spores and their relative protein mass, a protein yield estimate was conducted for each treatment (Table 1). The protein yields in micrograms per million basidiospores were approximately $0.161 ; 2.307$, and 3.582 for germination times of 0,2 , and 4 HAG, respectively.

\section{Protein extraction efficiency}

In order to verify if the developed protein extraction method produced protein with high quality and integrity, we resolved $30 \mu \mathrm{g}$ of each spore protein sample in a $12.5 \%$ SDS-PAGE gel. Proteins were visualized with Coomassie
Blue staining (Fig. 4). In all three treatments (0, 2, and 4 HAG), the observed protein profiles displayed well-resolved bands with molecular masses ranging from 10 to $200 \mathrm{kDa}$. Differences were observed between the 3 protein profiles; some bands were seen only after germination and other bands showed decreased intensity after germination (Fig. 4, arrows and dotted arrows, respectively). Throughout the protein profiles, variations in intensity of some bands can also be observed.

\section{D-PAGE analysis}

We further analyzed the protein profile of $M$. perniciosa ungerminated spores (0 HAG) in a 2DE gel (Fig. 5). Samples were analyzed in triplicate. Protein spots were distributed in a broad non-linear $\mathrm{pH}$ range from 3 to 10 . Gel analysis using Image Master V.6 (GE Healthcare) software revealed the presence of 549, 534, and 559 spots in gel replicates 1,2 , and 3, respectively. Most observed proteins (about $63.4 \%$ ) had a molecular weight between 30 and $60 \mathrm{kDa}$ (data not shown). A dispersion graph was generated with a positive correlation of 0.95 between the SDS-PAGE replicates (Additional file 4: Figure S2).

\section{Identified proteins in ungerminated basidiospores}

From the 2DE gel containing protein samples from ungerminated spores, a total of 400 spots were excised, processed, and analyzed using a mass spectrometer (Nano ESI Q-TOF, Micromass/Waters, Milford, MA, USA); 178 proteins were identified. Spots isolated from the 2DE gel are indicated with arrows in Fig. 5. The identification of the spots is shown in Additional file 5: Table S2.

The 178 proteins identified from the ungerminated basidiospores were classified into functional categories, which are displayed in Fig. 6. The category containing the highest number of identified proteins is related to energy processes (36\%), followed by proteins related to oxidoreductase activity (13.56\%), proteins linked to metal ions

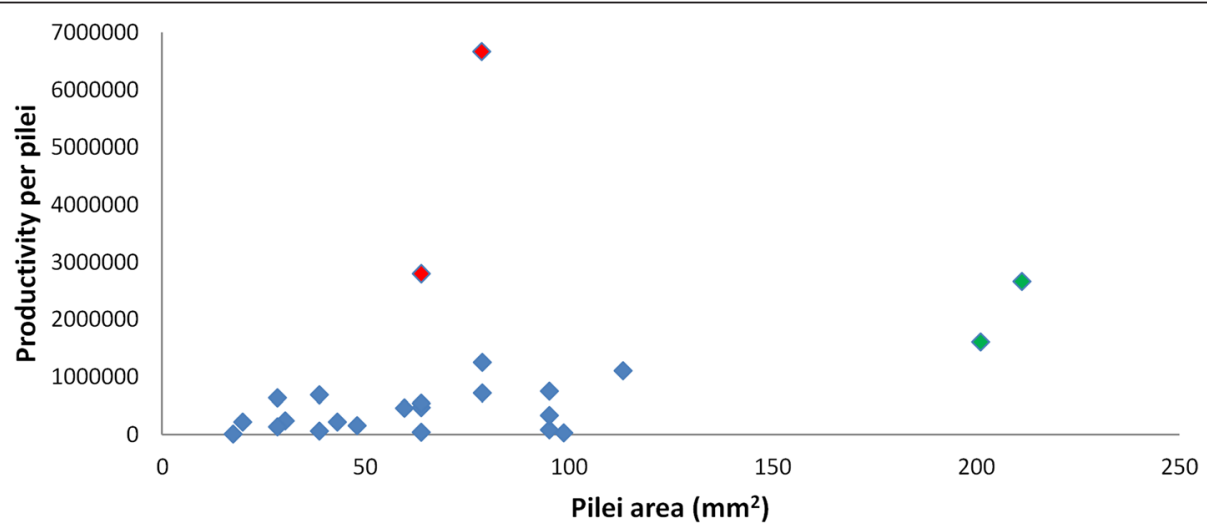

Fig. 2 Moniliophthora perniciosa basidiospore productivity per pileus area. Red dots represent categories with more distant values compared to the average overall analysis (black dots) 

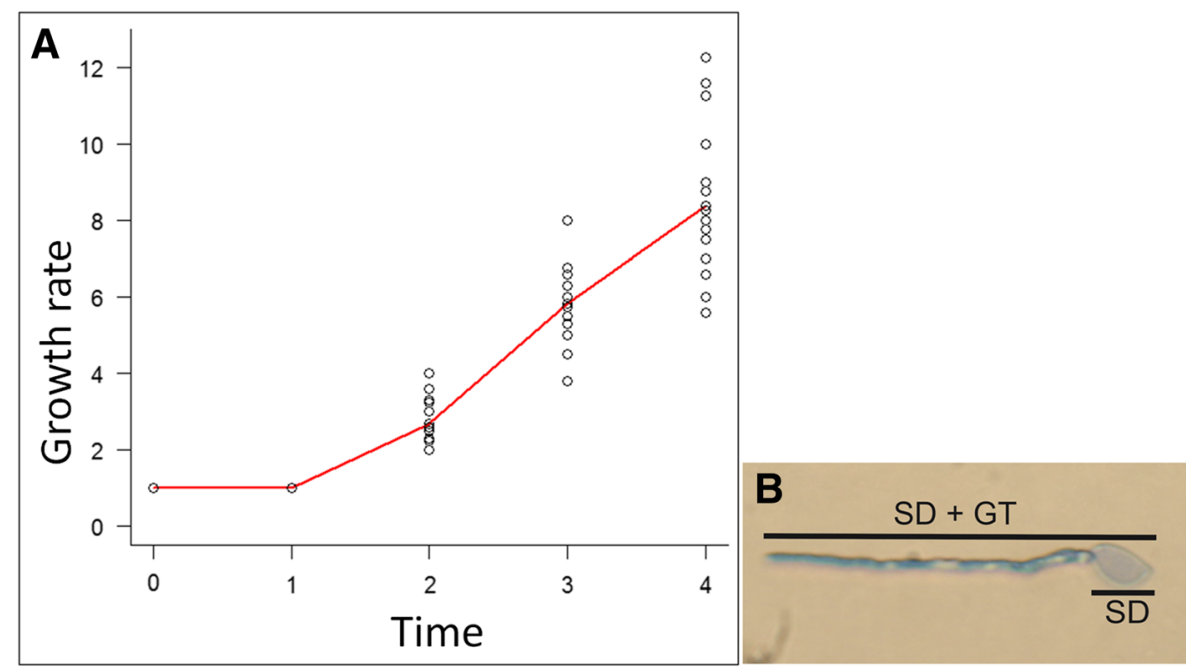

Fig. 3 Moniliophthora perniciosa germ tube growth rate. a Growth rate of the spores during germination, expressed as the ratio between length of spore plus germ tube $(\mathrm{SD}+\mathrm{GT})$ and spore diameter $(\mathrm{SD})$. [Ratio $=(\mathrm{SD}+\mathrm{GT}) / \mathrm{SD}$ ]. $\mathbf{b}$ Growth scale of $M$. perniciosa basidiospores during germination. SD corresponds to the highest spore diameter, and SD+GT to spore length plus germ tube. The image was obtained $4 \mathrm{~h}$ after germination

$(8.57 \%)$, ribosome structural components $(8 \%)$, proteins related to GTP linkage (8\%), electron-carrying proteins $(6 \%)$, proteins with GTPase activity $(6 \%)$, proteins related to protein folding (6\%), and co-factors (5.16\%).

\section{Description of the interaction network}

The protein-protein interaction network that used orthologous proteins of $U$. maydis displayed the presence of 1066 proteins (nodes) and 22,769 connectors, with a confidence level of 0.6 . Of the 72 orthologous sequences of proteins found from the reciprocal BLAST with $U$. maydis, 66 were located within the network (Additional file 3: Table S4) and they are represented in higher node sizes (Fig. 7). A survey of the gene ontology for the biological processes of all proteins in the network was performed using the BiNGO plugin.

A cluster analysis was performed with the MCode plugin, which resulted in clusters with scores higher than 2.5 (Fig. 7a-h; Additional file 6: Table S3). The main cluster (cluster 1) represented proteins related to protein synthesis or degradation. This cluster contains 178 proteins and 8,157 connectors. Seven orthologous proteins identified in this cluster (RPS1, UM00868.1, UM05990.1, RPS0, UM03578.1, UM01318.1 and UM04986.1) also interact with other proteins. Those interacting proteins are highlighted with bigger circles inside the cluster (Fig. 7a). Cluster 2 represents 35 proteins and 519 connectors. Two orthologous proteins are part of that cluster (UM02562.1 and tef1). Protein UM02562.1 is a hub (represented by the medium gray color), and it interacts with several other proteins that are associated with cell metabolism (Fig. 7b). Cluster 3 contains 25 proteins and 298 connectors. In this cluster, only one orthologous protein was grouped-UM05993.1-a mitochondrial protein represented as a hub-bottleneck which interacts with many other proteins associated with cellular respiration (Fig. 7c). Cluster 4 presents 43 proteins and 416 connectors. All proteins in this cluster are related to biosynthesis and RNA processing. No orthologous proteins identified in this study were grouped in this cluster (Fig. 7d). Cluster 5, the smallest cluster, contained only 15 proteins, two of which were orthologous proteins identified through MS/MS. Orthologous protein UM00157.1 is a pyruvate kinase, and UM02776.1 is a

Table 1 Protein productivity of M. perniciosa ungerminated and germinated basidiospores

\begin{tabular}{llll}
\hline & \multicolumn{3}{l}{ Hours After Germination starts- HAG (treatments) } \\
\cline { 2 - 4 } & $0 \mathrm{~h}$ & $2 \mathrm{~h}$ & $4 \mathrm{~h}$ \\
\hline Number of basidiospores used & $7 \times 10^{9}$ & 1200 & $6.7 \times 10^{8}$ \\
Total protein obtained $(\mu \mathrm{g})$ & 1125 & 2.31 & 2400 \\
Protein yield for $10^{6}$ basidiospores $(\mu \mathrm{g})$ & 0.161 & 1122 & 3.58 \\
${ }^{a}$ Estimated number of pilei to produce $1050 \mu \mathrm{g}$ of protein & 16115 & 723 \\
\hline
\end{tabular}

Number of spores and protein yield

${ }^{a}$ Calculated considering the average productivity of 405.212 basidiospores per pileus for the one night-collection period (16 $\mathrm{h}$ of production). See Additional file 2 : Table S1 


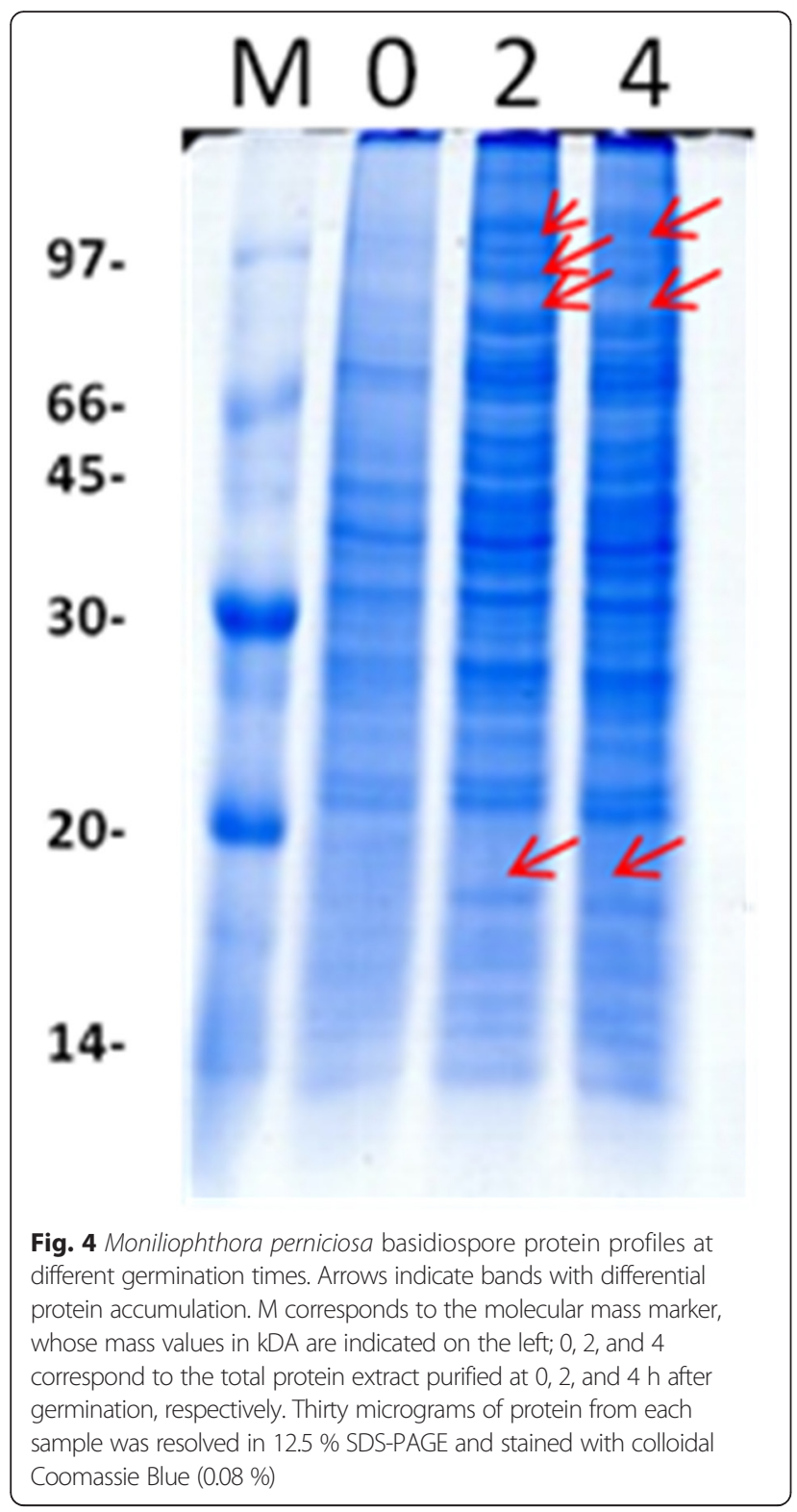

nucleoside diphosphate kinase that activates transcription. Those proteins were considered to be hub-bottlenecks, and they interact with many other proteins involved in transcriptional processing. Eighty proteins and 422 connectors form cluster 6, which cluster with the highest number of orthologous proteins: 10 (UM05090.1, UM04871.1, UM03951.1, UM00621.1, UM03356.1, UM03527.1, UM04971.1, UM045 62.1, UM00595.1, UM02462.1). Four of those proteins were considered to be hub-bottlenecks, and they interact with xmany other proteins that are involved in electron transport (Fig. 7f). Cluster 7 represented 75 proteins and 242 connectors. Seven orthologous proteins from the initial study were grouped in this cluster (UM01672.1, UM0068.1, UM0 0403.1, UM05379.1, UM05918.1, UM06453.1, UM04507.1). Protein UM00403.1 is considered a hub-bottleneck and seems to be a key protein for cell regulation, mainly for the regulation of actin filament polymerization (Fig. $7 \mathrm{~g}$ ). Cluster 8 has 47 proteins and 117 connectors. Four original orthologous proteins were placed in this group (UM02715.1, UM028991.1, UM03449.1, UM03734.1). Most proteins in this interaction group are involved in the biosynthesis of amino acids and cell division (Fig. 7h; Additional file 6: Table S3). Thirty-three orthologous proteins identified in this study were not found in any of the clusters (Fig. 7i). However, the analysis shows an interaction of proteins involved in important processes for the fungus, such as reproduction and primary hypha development (Fig. 7j). Proteins such as UM01366.1, UM02442.1, UMS2, UM06217.1 directly interact with each other and with several other proteins involved in chitin wall formation and filament development. Three unclustered proteins were considered as hub-bottlenecks. They are UM06217.1, tub1, and UM02442.1. UM06217.1 is an actin protein, which directly interacts with nine other proteins in this study and 130 other proteins distributed all over the network (Additional file 7: Figure S3).

\section{Discussion}

This is the first study of the characterization of $M$. perniciosa basidiospore proteins, probably due to the difficulty in obtaining protein from spores in sufficient quantity and homogeneity to conduct proteomic studies. During the production of basidiocarps for this study, the productivity of basidiospores per pileus was analyzed for different basidiomes size categories (which were expressed per area in Fig. 2).

We have shown that the yield of basidiospores per pileus is highly variable, but the average is approximately 400,000 basidiospores per pileus during a one-night collection. Considering the protein yield for each germination time-point, the number of basidiomes needed to conduct proteomic analyses was estimated. The results showed increasing protein yield of $M$. perniciosa basidiospores during the germination process (Table 1). The final protein mass obtained for ungerminated spores was enough to prepare three replicates of the 2DE gel, as each replicate requires $350 \mu \mathrm{g}$. A much larger number of basidiomes is required to obtain enough protein to analyze ungerminated basidiospores in comparison to germinated ones (approximately 222 times more), according to the estimated protein yield that was assessed for germination times of 2 and $4 \mathrm{~h}$. Some fungal spores require protein synthesis during the early development phase so biosynthesis of essential enzymes involved in respiratory pathways can occur [44-46]. The high number of spores released per pileus may be related to the high dispersion power of the fungus, but the determining factor for the epidemiology of the disease is the presence or absence of conditions such as host phenology and basidiocarp production [47]. Furthermore, the interaction between plant characteristics and a favorable climate (alternating dry 


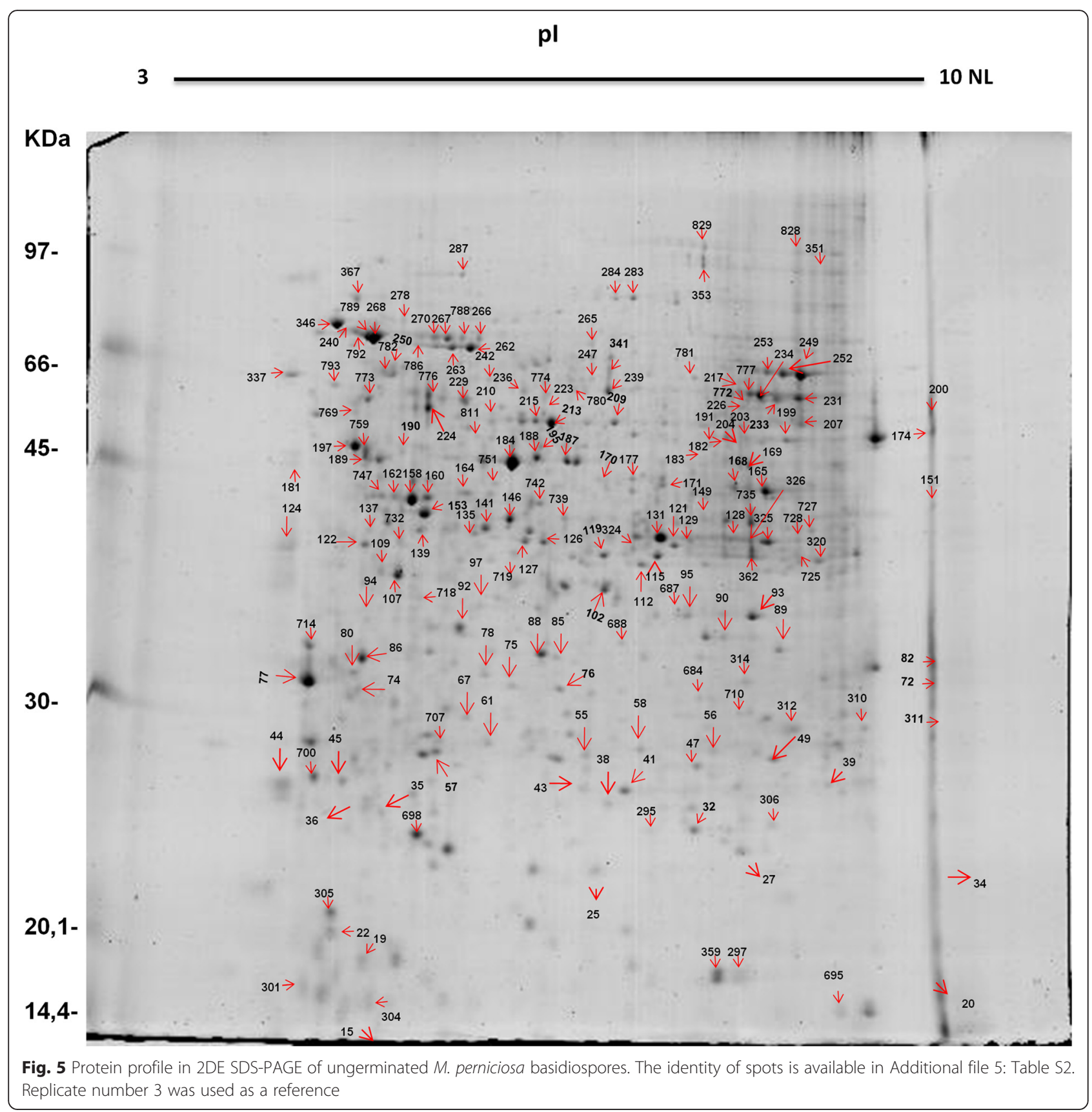

and humid periods) is of fundamental epidemiological importance for this disease [48].

Around $90 \%$ of the basidiospores stored in $16 \%$ glycerol germinated when the solution was diluted to a glycerol concentration of $3 \%$, similar to observations by Frias et al., [8]. This can be explained by the fact that a glycerol concentration of $16 \%$ keeps $\mathrm{H}_{2} \mathrm{O}$ from entering the basidiospore, hindering germination. The swelling after glycerol concentration was reduced to $3 \%$ may be explained by the inflow of water from the external environment [49]. Trehalose degradation and glycerol biosynthesis in other fungi (such as yeasts and $A$. nidulans) increase the internal osmotic potential, which favors water absorption [50, 51]. In that context, we have identified three orthologous proteins that were not clustered in the interaction network. These proteins are GTPases UM05511.1 and UM00756.1, and actin UM06217.1, which directly interacts with MAP Kinase HOG1 (high-osmolarity glycerol). The HOG pathway was first discovered in the yeast Saccharomyces cerevisiae, and it seems to be activated to regulate hyperosmotic stress [52]. Tolerance to hyperosmotic stress may be a fundamental process in the life cycle of filamentous fungi [53].

As most fungi have a resistant and rigid cell wall, the protein extraction process is a key step for proteomic 


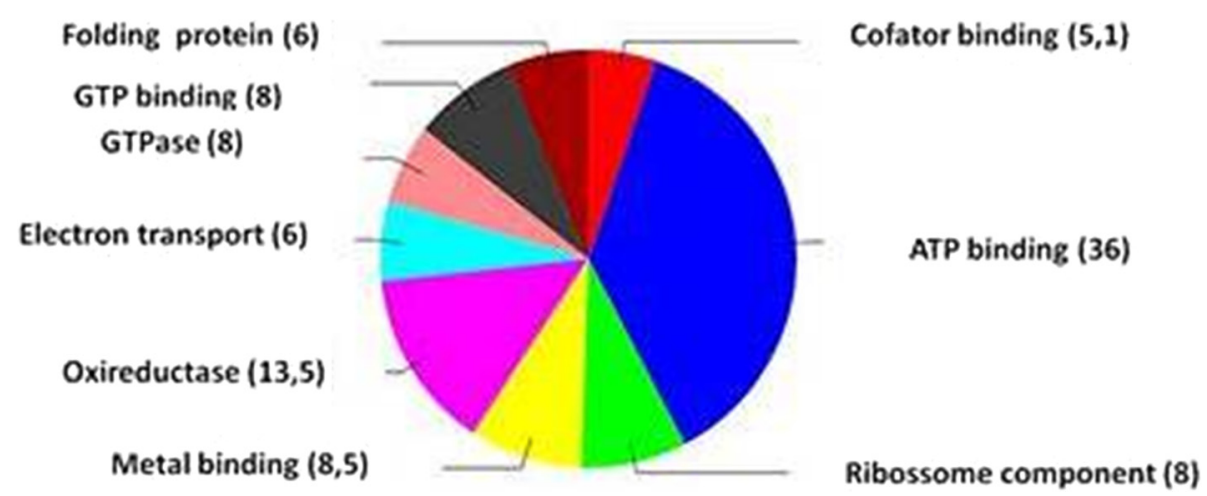

Fig. 6 Representative functional classification of proteins that were expressed in M. perniciosa ungerminated basidiospores

studies of these microorganisms [24]. Basidiospore protein extraction with phenol seemed very efficient, and resulted in well-resolved and well-defined bands with no drag, indicating a lack of interfering compounds as seen in the SDS-PAGE gel (Fig. 4). Extraction with phenol resulted in high quantities of soluble protein and good reproducibility in both the first and second dimensions (Fig. 5). An efficient phenol-based extraction solubilizes membrane proteins, removes nucleic acids, and minimizes proteolysis.

Taking into account the difficulty in obtaining the biological samples, we may consider the quantity (178) of proteins identified through mass spectrometry to be satisfactory, and within the averages found by other authors. Noir et al., identified 180 proteins by 2DE analysis of Blumeria graminis conidiospore spots, the phytopathogenic fungus responsible for barley mildew [25]. Quin et al., identified 24 conidium proteins in entomopathogenic fungus Nomuraea rileyi isolated from infected silkworms [54] and Barros et al., identified 65 proteins in conidia of the entomopathogenic fungus Metarhizium acridum to build a reference map [55].

Identical or similar functional classifications for different spots are common in proteomic studies that use 2DE SDS-PAGE [25]. This may be caused by post translational modifications (PTMs) in products of the same gene, or the presence of protein isoforms coded for different genes [56]. Phosphorylation is a very common and dynamic PTM in cell biochemical processes. Phosphorylation can regulate increases or decreases in enzyme activity, support protein migration to other cell compartments to allow for protein-protein interaction, and also mark proteins for degradation [57].

\section{Identified proteins and interaction network}

Proteomic analysis using systems biology may give us a broad view of the main process, which occur in fungi before they invade plant tissues. Most proteins we identified in the basidiospore are involved in cell energy metabolism
(Fig. 6). This may also be visualized by the 10 orthologous proteins that are part of cluster 6 , all of which are related to cell metabolism (Fig. 7h).

Metabolic polypeptides are much more abundant in soluble protein samples, and are well represented in proteomic studies. This also applies to fungal proteome analyses, for example, where proteins involved in metabolic processes accounted for approximately $66 \%$ of the total proteins identified in uredospores of phytopathogenic basidiomycete Uromyces appendiculatus [58]. Similarly, proteins responsible for metabolism during the germinative process accounted for $75 \%$ of the total proteins identified in the analysis of conidiospores of Blumeria graminis [25].

Within the protein group that relates to cell metabolism, cluster 7 , four proteins were considered to be hubbottlenecks (UM04971.1, fumarate reductase; UM04562.1, aspartate aminotransferase; UM02461.1, dihydrolipoyl dehydrogenase; and UM00595.1, aspartate aminotransferase). Those proteins play a key role in the citric acid cycle.

Although the majority of identified proteins are not related to protein synthesis or degradation (Fig. 6), these proteins represent the largest cluster in the interaction network (Fig. 7a). Seven orthologous ribosome proteins were found. These proteins were grouped in this cluster (RPS1, UM00868.1, UM05990.1, RPS0, UM03578.1, UM01318.1, UM04986.1), and they also interact with other proteins. Ribosome protein UM04986.1 is the hub-bottleneck that makes the most direct interactions. It is involved in 182 direct interactions with proteins that are mainly distributed with proteins from cluster 4 , and some unclustered ones (Additional file 8: Figure S4). Among those are proteins involved in RNA transcription and processing (PB1, UM06156.1, UM06331.1, UM05334.1, UM03058.1, UM0 2324.1, UM02903.1, UM04722.1).

Proteins considered as hub-bottlenecks, associated in cluster 5, play a key role in transcriptional processes (RPB1; UM03988.1). This may be related to the demand for proteins that are responsible for filament development. For example, protein UM00157.1, a hub-bottleneck protein in 


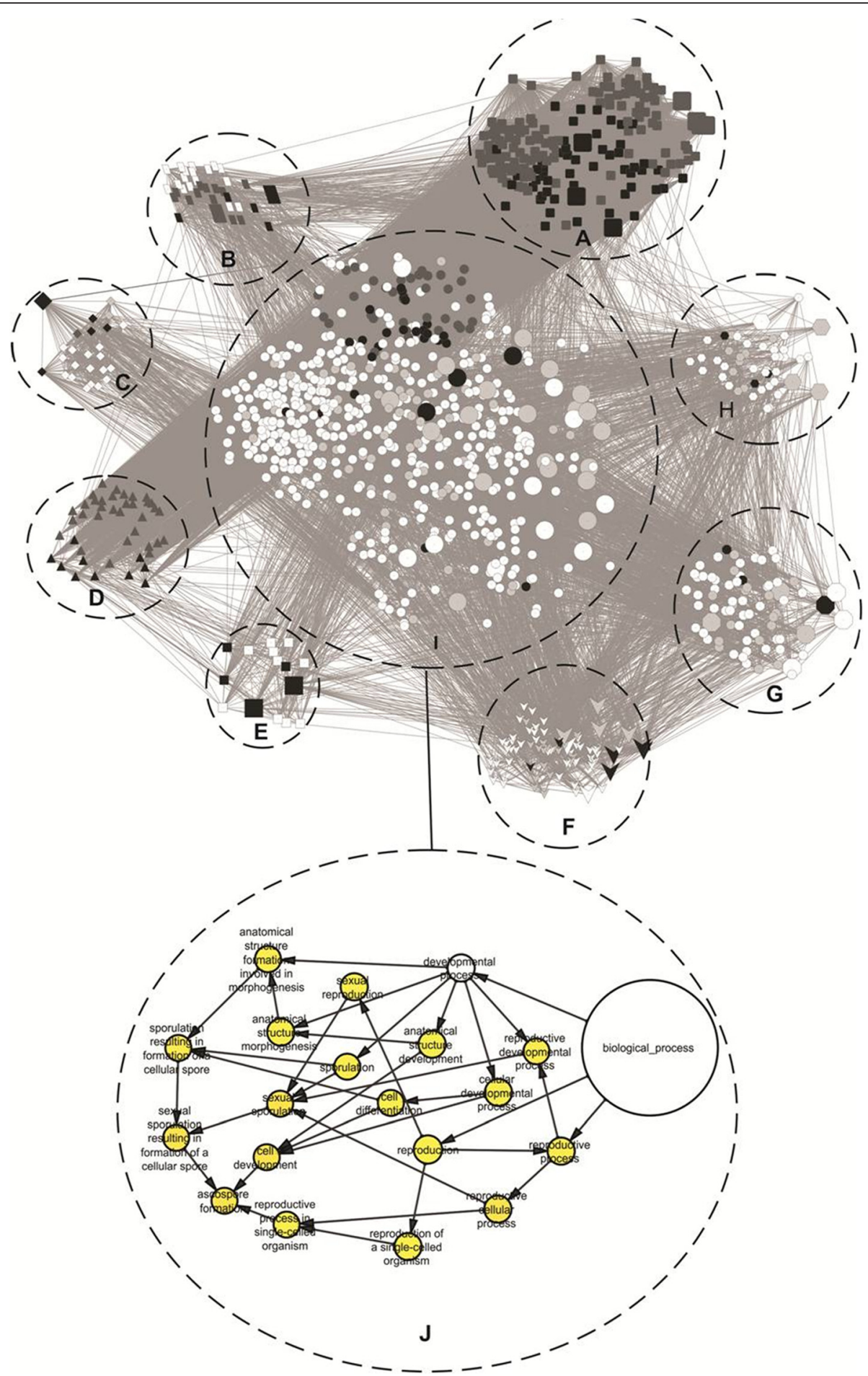

Fig. 7 Interaction network of proteins in Moniliophthora perniciosa basidiospores. a Cluster 1: proteins that are related to protein synthesis and degradation. b Cluster 2: proteins that are related to cell metabolism. c Cluster 3: proteins that are related to cell respiration. d Cluster 4: proteins that are involved in RNA processing. e Cluster 5: proteins that are related to gene transcription and expression. $\mathbf{f}$ Cluster 6: proteins that are involved in ion transportation. $\mathbf{g}$ Cluster 7: proteins that are involved in cytoskeleton regulation and organization. $\mathbf{h}$ Cluster 8: proteins that are involved in amino acid biosynthesis. i Unclustered proteins. Each geometric shape represents a group, as separated by its MCODE. Bigger sized shapes represent orthologous proteins that were identified in this study. Dark, medium, and light gray tones represent the proteins that are considered hub-bottlenecks, hub, and bottlenecks, respectively. $\mathbf{j}$ Representations of the main biological processes that are performed by proteins that were not grouped by BiNGOA plugin. The arrows represent the ranking of biological processes from most general to most specific 
group 5, is a pyruvate kinase that directly interacts with key proteins related to hypha growth and development of filamentous fungi such as protein $\mathrm{UAC1}$, an adenylate cyclase that was isolated and classified in $U$. maydis (Additional file 9: Figure S5). Haploid lineages of $U$. maydis, in which the UAC1 gene was deleted, exhibit a stable filamentous phenotype and loss of pathogenic capacity [59].

Half of the orthologous proteins (33) identified in this study were not clustered in the network, but several of them play a very important role in hypha development and branching. Actin UM06217.1 is considered a hubbottleneck protein, and it directly interacts with 139 other proteins that are distributed all over the network (Additional file 7: Figure S3). Among the proteins that are part of that interaction, some of them deserve special attention for being very important in the invasive growth of hyphae. One such protein is CDC42. Yeast mutants ectopically expressing CDC42, were unable to form invader hyphae filaments in response to high temperature [60]. Another protein deserving attention is UAC1. When the gene coding for this protein was deleted in $U$. maydis, the mutant strains displayed a branched hyphal phenotype and a loss of fungal pathogenicity [61]. RAC1 expression is involved with the shape of the septum and hypha growth in $U$. maydis [62]. The actin UM06217.1 also is able to interact with the MAP kinase CHK1, which operates in DNA damage repair checkpoints during $\mathrm{G} 2$, and plays a key role in the regulation of the cell cycle [63]. Finally, protein KPP6 should be mentioned. According to Brachmann [64], mutant strains deleted for this gene may form normal appressoria, but are unable to penetrate into the plant cuticle. KPP6 may respond to a plant signal by regulating the necessary genes for efficient penetration into the plant tissue. These aforementioned proteins are part of fundamental processes such as sporulation, reproduction, and cell differentiation for the successful start of spore germination on the surface of plants (Fig. 7i). The interactions among these proteins may provide insights on how the molecules play during the early fungal development and indicates target proteins to drug development and protein activity inhibition in order to decrease the $M$. perniciosa pathogenicity and disease control.

\section{Conclusions}

In summary, in this study, we showed that the productivity of $M$. perniciosa basidiospores per pileus area is highly variable, but the average is 405.212 basidiospores per pileus during a one-night collection. The protein yield per spore increases during the $4 \mathrm{~h}$ after germination. The numbers of basidiospores $7 \times 10^{9}, 5.2 \times 10^{8}$, and $6.7 \times 10^{8}$ obtained in the 0,2 , and 4 HAG groups, respectively, are sufficient to obtain enough protein mass for the three 2DPAGE replicates. The protein extraction method that is based on sedimentation, sonication with dense SDS, and phenolic extraction, which was utilized in this study, was effective, presenting good resolution and reproducibility for $M$. perniciosa basidiospores.

We also present the first 2D-PAGE reference map of proteins expressed during germination, showing the protein types that are likely involved in fungal development. This fungal developmental stage is very important, as it represents the first contact between plant and pathogen. We identified orthologous proteins in $U$. maydis such as hub-bottleneck ribosome protein UM04986.1, actin UM06217.1, and pyruvate kinase UM00157.1, the interaction of which helps play a very important role in hypha development and branching. The identification of proteins contained in the reference gel elucidated many potential molecular interactions involved in the initial metabolic processes during fungal development.

In addition, this protein network may also be used to determine proteins involved in fungal and phytopathogenic processes that are candidates for targeting with diseasecontrolling drugs. This information guides the planning of experiments that involve proteome analyses of $M$. perniciosa fungus basidiospores.

\section{Additional files}

Additional file 1: Figure S1. Workflow to present the steps taken in this study. (JPG $1055 \mathrm{~kb}$ )

Additional file 2: Table S1. Basidiospore production and protein yield analyzed. (XLS $48 \mathrm{~kb}$ )

Additional file 3: Table S4 Orthologous sequences of genes from Ustilago maydis used to construct the network along with their annotations. (XLS $33 \mathrm{~kb}$ )

Additional file 4: Figure S2. Dispersion graph among the SDS-PAGE replicates. (TIF $489 \mathrm{~kb}$ )

Additional file 5: Table S2. Identification of spots marked with arrows on the reference gel. (XLS $213 \mathrm{~kb}$ )

Additional file 6: Table S3. Gene ontology for the biological processes of all proteins in the network using BiNGOA plugin, and the cluster analysis performed with the MCode plugin. (XLSX 145 kb)

Additional file 7: Figure S3. Interaction of actin UM06217.1 which directly interacts with nine other proteins in this study and other 130 proteins distributed all over the network. (TIF $1163 \mathrm{~kb}$ )

Additional file 8: Figure S4. Direct interactions of the ribosome hub-bottleneck protein UM04986.1. (TIF 1240 kb)

Additional file 9: Figure S5. Interaction of hub-bottleneck protein UM00157.1 with key proteins related to hypha growth and development of filamentous fungi protein UAC1. (TIF $1045 \mathrm{~kb}$ )

\section{Abbreviations}

BOD, biochemical oxygen demand; CEPEC, Centro de Pesquisas do Cacau; CEPLAC, Comissão Executiva do Plano da Lavoura Cacaueira; HAG, hours after germination; SDS-PAGE, sodium dodecyl sulfate-Polyacrylamide gel electrophoresis

\section{Acknowledgements}

This work was supported by grants from FAPESB (Fundação de Apoio à Pesquisa do Estado da Bahia). We thank Fabienne Micheli (State University of Santa Cruz 
and (irad) and Claudia Fortes Ferreira for critically reading the manuscript. Thanks to the phytopathology laboratory staff in CEPEC/CEPLAC for support with the collection of basidiospores, to Louise Araujo Brito and Renata for their assistance in basidiospore collection. C. P. Pirovani and K. P. Gramacho, were supported by research fellowships from $\mathrm{CNPq}(\mathrm{Pq}-2$ and $\mathrm{Pq}-1$; respectively).

\section{Funding}

This work was supported by the grants of Bahia Research Foundation (FAPESB) $n^{\circ}$ PNE0005/2011 and by the National Council for Scientific Development (CNPq) n 305309/2012-9.

\section{Authors' contributions}

$J H M$ and CPP were responsible for designing the experiments and writing the manuscript. ECS and KPG participated in achievement and collection of biological samples. ECS, ASS, and EMAS participated in acquisition of data, bioinformatics analysis, and systems biology analysis. FCA and KPG participated in critical revisions for important intellectual content. All authors read and approved the final version of the manuscript.

\section{Competing interests}

The authors declare that they have no competing interests.

\section{Consent to publish}

Not applicable.

\section{Ethics approval and consent to participate}

The Internal Committee of Ethics and Biosecurity of the State University of Santa Cruz approved this study (Protocol Number 05/2013).

\section{Availability of supporting data}

The data and materials supporting the conclusions of this article are also included within the article and its additional files.

\section{Author details}

'Departamento de Ciências Biológicas, Universidade Estadual de Santa Cruz, Ilhéus, Bahia, Brazil. ${ }^{2}$ Centro de Biologia Molecular e Engenharia Genética (CBMEG), Universidade Estadual de Campinas, Campinas, SP, Brazil. ${ }^{3}$ Centro de Pesquisas do Cacau - CEPEC, Comissão Executiva do Plano da Lavoura Cacaueira- CEPLAC, Ilhéus, Bahia, Brazil.

\section{Received: 1 February 2016 Accepted: 15 June 2016}

\section{Published online: 24 June 2016}

\section{References}

1. Hebbar KP. Cacao diseases: a global perspective from industry point of view. Phytopathology. 2007;97(12):1658-63.

2. Mc A, Phillips-Mora W. The causal agents of witches' broom and frosty pod rot of cacao (chocolate, Theobroma cacao) form a new lineage of Marasmiaceae. Mycologia. 2005;97(5):1012-22.

3. Luz EDMN, Bezerra JL, Resende MLV, Oliveira ML. Doenças do cacaueiro. In: Vale FXR, Zambolim L, editors. Controle de doenças de plantas. Viçosa: UFV/ Imprensa Universitária; 1997. p. 611-6.

4. Frias GA, Purdy LH, Schimidt RA. Infection biology of Crinipellis perniciosa on vegetative flushes of cacao. Plant Dis. 1991;75(6):552-6.

5. Sena K, Alemanno L, Gramacho KP. The infection process of Moniliophthora perniciosa in cacao. Plant Pathol. 2014;63(6):1272-81.

6. Bastos CN, Andebrhan T. In vitro production of basidiospores of Crinipellis perniciosa, the causative agent of witches' broom disease of cocoa. T Brit Mycol Soc. 1987;88:3,406-09.

7. Niella GR, Resende ML, Castro HA, Silva LHCP, Carvalho JA. Improvement of artificial production methodology basidiocarps of Crinipellis perniciosa. Braz Phytophathol. 1999;24:523-27.

8. Frias GA, Purdy LH, Schimidt RA. An inoculation method for evaluating resistance of cacao to Crinipellis perniciosa. Plant Dis. 1995;79:787-91.

9. Macagnan D, Romeiro RS, Pomella AW. Inhibition of Crinipellis perniciosa basidiospore germination by volatile compounds produced by five actinomycetes phylophaneresidents of cocoa. Summa Phytopathol. 2009;35:140-42.

10. Lima LS, Gramacho KP, Carels N, Novais R, Gaiotto FA, Lopes UV, Gesteira AS, Zaidan HA, Cascardo JCM, Pires, JL, Micheli F. Single nucleotide polymorphisms from Theobroma cacao expressed sequence tags associated with witches' broom disease in cacao. Genet Mol Res. 2009;8:799-808.
11. Alvim FC, Mattos EM, Pirovani CP, Gramacho KP, Pungartnik C, Brendel M, Cascardo JCM, Vincentz M. Carbon source-induced changes in the physiology of the cacao pathogen Moniliophthora perniciosa (Basidiomycetes) affect mycelial morphology and secretion of necrosis-inducing proteins. Genet Mol Res. 2009;8(3):1035-50.

12. Mondego JM, Carazzolle MF, Costa GG, Formighieri EF, Parizzi LP, Rincones J, Cotomacci C. A genome survey of Monilliophthora perniciosa gives new insights into Witches' Broom Disease of cacao. BMC Genomics. 2008;8:548.

13. Rincones J, Scarpari LM, Carazzolle MF, Mondego JM, Formighieri EF, Barau JG, Costa GG, Carraro DM, Brentani HP. Differential gene expression between the biotrophic-like and saprotrophic mycelia of the witches' broom pathogen Moniliophthora perniciosa. Mol Plant Microbe Interact. 2008:21:891-908

14. Gesteira AS, Micheli F, Carels N, Da Silva AC, Gramacho KP, Schuster I, et al. Comparative analysis of expressed genes from cacao meristems infected by Moniliophthora perniciosa. Ann Bot. 2007;100:129-40.

15. Garcia O, Macedo JAN, Tibúrcio R, Zaparoli G, Rincones J, Bittencourt LMC, et al. Characterization of necrosis and ethylene-inducing proteins (NEP) in the basidiomycete Moniliophthora perniciosa, the causal agent of witches' broom in Theobroma cacao. Mycol Res. 2007;111:443-55.

16. Lopes MA, Gomes DS, Koblitz MGB, Pirovani CP. Cascardo JCM, Goésneto A, et al. Use of response surface methodology to examine chitinase regulation in the basidiomycete Moniliophthora perniciosa. Mycol Res. 2008;112:399-406.

17. Pirovani CP, Carvalho HA, Machado RC, Gomes DS, Alvim FC, Pomella AW, Gramacho KP, Cascardo JC, Pereira GA, Micheli F. Protein extraction for proteome analysis from cacao leaves and meristems, organs infected by Moniliophthora perniciosa, the causal agent of the witches' broom disease. Electrophoresis. 2008:29:391-401.

18. Menezes SP, Silva EMA, Lima EM, Sousa AO, Andrade BS, Lemos LSL, et al. The pathogenesis-related protein PR-4b from Theobroma cacao presents RNase activity, $\mathrm{Ca} 2+$ and Mg2+ dependent-DNase activity and antifungal action on Moniliophthora perniciosa. BMC Plant Biol. 2014;14:161.

19. Zaparoli G, Cabrera OG, Medrano FJ, Tiburcio R, Lacerda G, Pereira GG, et al. Identification of a second family of genes in Moniliophthora perniciosa, the causal agent of witches' broom disease in cacao, encoding necrosisinducing proteins similar to cerato-platanins. Mycol Res. 2009;113:61-72.

20. Barsottini MRO, Oliveira JF, Adamoski D, Teixeira PJPL, Prado PFV, Tiezzi HO, et al. Functional diversification of cerato-platanins in Monilliophthora perniciosa as seen by differential expression and protein function specialization. Mol Plant Microbe Interact. 2013;26:1281-93.

21. Teixeira PJPL, Thomazella DPT, Vidal RO, Prado PFV, Reis O, Baroni RM, et al. The fungal pathogen Moniliophthora perniciosa has genes similar to plant pr-1 that are highly expressed during its interaction with cacao. PloS One. 2012. doi:10.1371/journal.pone.0045929.

22. Silva FAC, Pirovani CP, Menezes SP, Pungartnik C, Santiago AS, Costa MGC Proteomic response of Moniliophthora perniciosa exposed to pathogenesisrelated protein-10 from Theobroma cacao. GMR. 2013;12:4855-68.

23. Teixeira PJPL, Thomazella DPT, Reis O, Prado PFV, Rio MCS, Fiorin GL, et al. High-Resolution Transcript Profiling of the Atypical Biotrophic Interaction between Theobroma cacao and the Fungal Pathogen Moniliophthora perniciosa. Plant Cell. 2014:26:4245-69.

24. Bhadauria $V$, Zhao WS, Wang $L X$, et al. Advances in fungal proteomics. Microbiol Res. 2007;162:193-200.

25. Noir S, Colby T, Harzen A, Schmidt J, Panstruga R, et al. A proteomic analysis of powdery mildew (Blumeria graminisf.sp.hordei) conidiospores. Mol Plant Pathol. 2009:10:223-36

26. Oh YT, Ahn CS, Kim JG, Ro HS, Lee CW, Kim JW. Proteomic analysis of early phase of conidia in Aspergillus nidulans. Fungal Genet Biol. 2010;47:246-56.

27. El-akhal MR, Colby T, Cantoral JM, Harzen A, et al. Proteomic analysis of conidia germination in Colletotrichum Acutatum. Arch Microbiol. 2013;195:227-46.

28. Cassman M. Barriers to progress in systems biology. Nature. 2005;438:1079.

29. Carvunis AR, Roth FP, Calderwood MA, Cusick ME, Superti-Furga G, Vidal M. "Interactome networks", in Handbook of Systems Biology. In: Walhout M, Vidal M, Dekker J, editors. Concepts and Insights. Amsterdam: Elsevier Inc; 2013. p. 45-60.

30. Koschützki D, Schwöbbermeyer H, Schreiber F. Ranking of network elements based on functional substructures. J Theor Biol. 2007;248:471-79.

31. Wasserman S, Faust K. Social network analysis: methods and applications. Cambridge: Cambridge Univ. Press; 1994.

32. Yu H, Kim PM, Sprecher E, Trifonov V, Gerstein M. The importance of bottlenecks in protein networks: correlation with gene essentiality and expression dynamics. PLoS Comput Biol. 2007;3:59. 
33. Boone C, Bussey $\mathrm{H}$, Andrews BJ. Exploring genetic interactions and networks with yeast. Nat Rev Genet. 2007;8:437-49.

34. Breitkreutz A, Choi H, Sharom JR, Boucher L, Neduva V, Larsen B, et al. A Global Protein Kinase and Phosphatase Interaction Network in Yeast. Science. 2010;21:1043-6.

35. Carvalho HAS, Silva EM, Santos SC, Micheli F. Polygalacturonases from Moniliophthora perniciosa are regulated by fermentable carbon sources and possible post-translational modifications. Fungal Genet Biol. 2013;60:110-21.

36. Meyer Y, Grosset J, Chartier Y, Cleyet-Marel JC. Preparation by twodimensional electrophoresis of proteins for antibody production: antibodies against proteins whose synthesis is reduced by auxin in tobacco mesophyll protoplasts. Electrophoresis. 1988;9:704-12.

37. Pirovani CP, Santiago AS, Santos LS, Micheli F, Margis R, Gesteira AS, et al. Theobroma cacao cystatins impair Moniliophthora perniciosa mycelial growth and are involved in postponing cell death symptoms. Planta. 2010;232:1485-97.

38. Laemmli UK. Cleavage of structural proteins during the assembly of the head of bacteriophage T4. Nature. 1970;227:680-85.

39. Martinez-Espinoza AD, Garcia-Pedrajas MD, Gold SE. The Ustilaginales as plant pests and model systems. Fungal Genet Biol. 2002;35:1-20.

40. Steinberg G, Perez-Martin J. Ustilago maydis, a new fungal model system for cell biology. Trends Cell Biol. 2008;18:61-7.

41. Ho ECH, Cahill MJ, Saville BJ. Gene discovery and transcript analyses in the corn smut pathogen Ustilago maydis: expressed sequence tag and genome sequence comparison. BMC Genomics. 2007;8:334.

42. Moreno-Hagelsieb G, Latimer K. Choosing BLAST options for better detection of orthologs as reciprocal best hits. Bioinformatics. 2008;24:319-24.

43. Shannon P, Markiel A, Ozier O, Baliga NS, Wang JT, Ramage D, et al. Cytoscape: a software environment for integrated models of biomolecular interaction networks. Genome Res. 2003;13:2498-504.

44. Osherov N, May G. Conidial germination in Aspergillus nidulans requires RAS signaling and protein synthesis. Genetics. 2000;155(2):647-56.

45. Cochrane W, Cochrane JC. Chlamydospore development in the absence of protein synthesis in Fusarium solani. Dev Biol. 1970;23:345-54.

46. Loo M. Some required events in conidial germination of Neurospora crassa. Dev Biol. 1976;54:201-13.

47. Andebrhan T. Rain water as a factor in the dissemination of basidiospores of Crinipellis perniciosa (Stahel) Singer within cacao trees. In: Proc. 10th Int. Cocao Res. Conf. p 363-66. Santo Domingo: Dominican Republic 1988, 925.

48. Purdy LH, Schmidt RA. Status of Cacao witches' broom: biology, epidemiology, and management. Annu Rev Phytopathol. 1996:34:573-94.

49. Griffin DH. Fungal physiology. 2nd ed. New York: Wiley-Liss; 1994.

50. Pahlman AK, Granath K, Ansell R, Hohmann S, Adler L. The yeast glycerol 3phosphatases Gpp1p and Gpp2p are required for glycerol biosynthesis and differentially involved in the cellular responses to osmotic, anaerobic, and oxidative stress. J Biol Chem. 2001;276:3555-63.

51. Svanstrom A, Melin P. Intracellular trehalase activity is required for development, germination and heat-stress resistance of Aspergillus niger conidia. Res Microbiol. 2013;164:91-9

52. Brewster JL, de Valoir T, Dwyer ND, Winter E, Gustin MC. An osmosensing signal transduction pathway in yeast. Science. 1993;259:1760-63.

53. Duran R, Cary JW, Calvo AM. Role of the osmotic stress regulatory pathway in morphogenesis and secondary metabolism in filamentous fungi. Toxins. 2010:2:367-81.

54. Quin L, Liu X, Li J, Chen H, Yao Q, Yang Z, Wang L, Chen K.. Protein profile of Nomuraea rileyi spore isolated from infected silkworm. Curr Microbiol. 2009;58:578-85.

55. Barros BHR, da Silva SH, Marquesa ER, Rosab JC, Yatsuda AP, Roberts DW, Braga GUL. A proteomic approach to identifying proteins differentially expressed in conidia and mycelium of the entomopathogenic fungus Metarhizium acridum. Fungal Biol. 2010;114:572-79.

56. Jensen ON. Interpreting the protein language using proteomics. Nat Rev Mol Cell Biol. 2006:7:391-403.

57. Wolschin F, Wienkoop S, Weckwerth W. Enrichment of hosphorylated proteins and peptides from complex mixtures using metal oxide/hydroxide affinity chromatography (MOAC). Proteomics. 2005;5:4389-97.

58. Cooper B, Garrett W, Campbell K. Shotgun identification of proteins from uredospores of the bean rust Uromyces appendiculatus. Proteomics. 2006; 6(8):2477-84.

59. Barrett KJ, Gold SE, Kronstad JW. Identification and complementation of a mutation to constitutive filamentous growth in Ustilago maydis. Mol Plant Microbe Interact. 1993;6:274-83.
60. Bassilana M, Blyth J, Arkowitz RA. Cdc24, the GDP-GTP exchange factor for Cdc42, is required for invasive hyphal growth of Candida albicans. Eukaryot Cell. 2003;2(1):9-18.

61. Gold SE, Brogdon SM, Mayorga ME, Kronstad JW. The Ustilago maydis regulatory subunit of a CAMP-dependent protein Kinase $1 \mathrm{~s}$ required for gall formation in Maize. Plant Cell. 1994;9:1585-94.

62. Mahlert M, Leveleki L, Hlubek A, Sandrock B, Bölker M. Rac1 and Cdc42 regulate hyphal growth and cytokinesis in the dimorphic fungus Ustilago maydis. Mol Microbiol. 2006:59(2):567-78.

63. O'Connel MJ, Raleigh JM, Verkade HM, Nurse P. Chk1 is a wee1 kinase in the G2 DNA damage checkpoint inhibiting cdc2 by $Y 15$ phosphorylation. EMBO J. 1997;16(3):545-54

64. Brachmann A, Schirawski J, Müller P, Kahmann R. An unusual MAP kinase is required for efficient penetration of the plant surface by Ustilago maydis. EMBO J. 2003:22(9):2199-210.

\section{Submit your next manuscript to BioMed Central and we will help you at every step:}

- We accept pre-submission inquiries

- Our selector tool helps you to find the most relevant journal

- We provide round the clock customer support

- Convenient online submission

- Thorough peer review

- Inclusion in PubMed and all major indexing services

- Maximum visibility for your research

Submit your manuscript at www.biomedcentral.com/submit
C) Biomed Central 